\title{
Thermodynamic analysis of a combined organic Rankine cycle and vapor compression cycle system activated with low temperature heat sources using low GWP fluids
}

\author{
Francisco Molés ${ }^{1, a}$, Joaquín Navarro-Esbría ${ }^{a}$ Bernardo Peris ${ }^{\mathrm{a}}$, \\ Adrián Mota-Babilonia, ${ }^{\mathrm{a}}$, Konstantinos (Kostas) Kontomaris ${ }^{\mathrm{c}}$ \\ ${ }^{a}$ ISTENER Research Group. Department of Mechanical Engineering and Construction, \\ Campus de Riu Sec s/n, University Jaume I, E12071, Castellón (Spain). \\ ${ }^{\text {b }}$ Departamento de Ingeniería Química y Nuclear, Universidad Politécnica de Valencia, \\ Camino de Vera 14, Valencia (Spain). \\ ${ }^{\mathrm{c}}$ DuPont Fluorochemicals R\&D, Wilmington, Delaware, USA.
}

\begin{abstract}
A combined organic Rankine cycle and vapor compression cycle (ORC-VCC) system activated by low temperature heat sources was studied. Two low GWP fluids were considered as working fluids for the VCC and two different low GWP fluids for the ORC. System performance was evaluated through computational modeling over different operating conditions. The computed thermal COP of the ORC-VCC system varied between 0.30 and 1.10 over the range of operating conditions studied. The computed electrical COP of the ORC-VCC system, defined as the ratio of the rate of cooling and the ORC pump power consumption, varied between 15 and 110 . The choice of VCC working fluid had only a limited influence on system thermal or electrical efficiency, with HFO-1234ze(E) presenting slightly better results. Use of HFO$1336 \mathrm{mzz}(\mathrm{Z})$ as the ORC working fluid resulted in slightly higher system thermal efficiencies and significantly higher system electrical efficiencies throughout the range of operating conditions studied.
\end{abstract}

Keywords: organic Rankine cycle; vapor compression cycle; thermally activated cooling; low temperature heat sources; low GWP fluids.

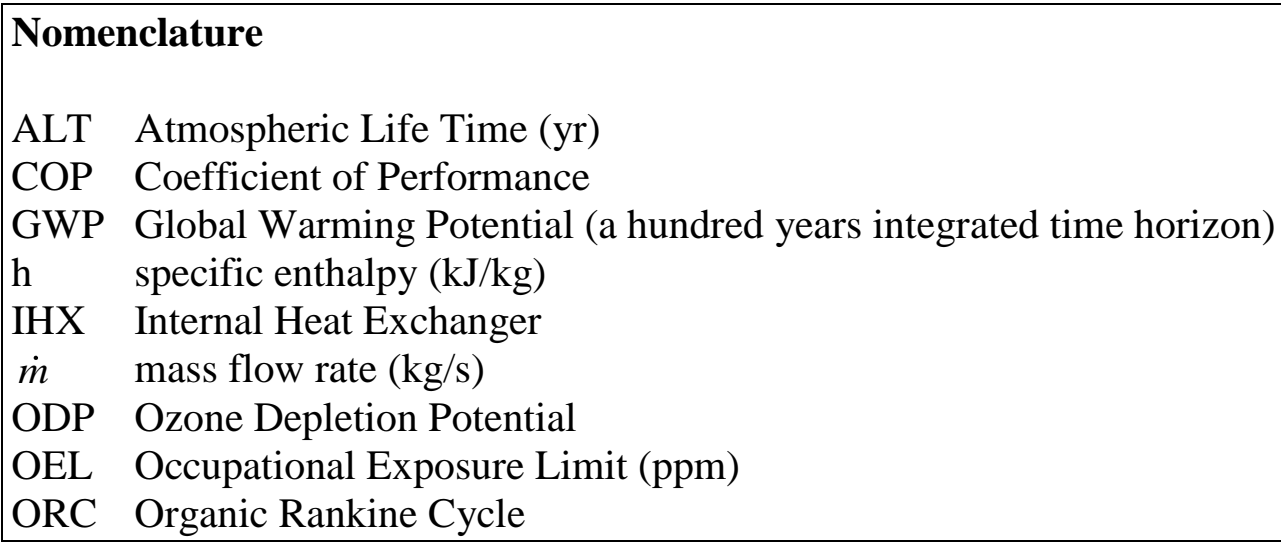

${ }^{1}$ Corresponding Author:

Tel: +34 964387529; fax: +34964728106.

E-mail address: molesf@uji.es 


\begin{tabular}{|ll|}
\hline $\mathrm{P}$ & pressure $(\mathrm{kPa})$ \\
$\mathrm{Q}$ & evaporator thermal power $(\mathrm{kW})$ \\
$\mathrm{s}$ & entropy $(\mathrm{kJ} / \mathrm{kgK})$ \\
$\mathrm{T}$ & temperature $(\mathrm{K})$ \\
$\mathrm{VCC}$ & Vapor Compression Cycle \\
$\mathrm{W}$ & mechanical power $(\mathrm{kW})$ \\
Greek & symbols \\
& \\
$\eta$ & efficiency \\
$\varepsilon$ & heat exchangers effectiveness \\
Subscripts \\
$\mathrm{c}$ & compressor \\
$\mathrm{E}$ & electrical \\
is & isentropic \\
$\mathrm{o}$ & overall \\
$\mathrm{p}$ & pump \\
$\mathrm{T}$ & thermal \\
$\mathrm{x}$ & expander \\
\hline
\end{tabular}

\section{Introduction}

The utilization of low temperature heat sources (such as solar, geothermal, biomass and waste heat recovery) can significantly contribute to reducing conventional, nonrenewable, energy consumption and relieving associated environmental problems. As a result, cooling technologies activated by low-grade heat have gained considerable interest [1].

Thermally activated cooling technologies include sorption (absorption and adsorption) cooling and desiccant cooling, among others [2]. Various experimental studies have been carried out in the literature reporting the performance of these systems. Regarding absorption ammonia/water technologies, Jakob et al. [3] analyzed experimentally a solar heat drive ammonia/water diffusion-absorption cooling machine with a coefficient of performance (COP) of 0.38 for air conditioning applications. The COP of single-stage $\mathrm{LiBr}-\mathrm{H}_{2} \mathrm{O}$ absorption chillers is generally higher: González-Gil et al. [4] reported the experimental evaluation of a direct air-cooled water/lithium bromide absorption prototype for solar air conditioning with a COP around 0.6. The cost of multi-stage absorption systems is considerably higher than that of single-stage systems, although Calise [5] reported that the economic profitability is higher for hottest climates. Diverse adsorption cooling prototypes operating with water/silica gel have been evaluated, as the work of Núñez et al. [6] that presented a small adsorption heat pump with a heating COP more than 1.5, meanwhile the cooling COP was about 0.5. Several novel ideas to use heat pipes in adsorption water chiller or ice maker were presented by Wang [7] that reported a cooling COP of 0.4 for a small scale adsorption water chiller driven by $85^{\circ} \mathrm{C}$. Regarding the experimental studies with activated carbon, Aghbalou et al. [8] estimated a COP of 0.144, while for other mixtures (like methanol/charcoal) Khattab [9] achieved $\mathrm{COP}$ values around 0.15. Substantial improvement in desiccant performance has been recently reported: Li et al. [10] reported a cooling COP of 0.95 for a two-stage solid 
desiccant adsorption system, while Xiong et al. [11] obtained a COP value of 0.97 with a two-stage liquid desiccant ( $\mathrm{LiBr}$ ) assisted by $\mathrm{CaCl}_{2}$. Finally, ejector cycles can provide cooling with inexpensive equipment, and they are easy to construct and maintain. Ma et al. [12] achieved a cooling COP value of 0.5 with an ejector cycle using water as working fluid.

Compared to other thermally activated cooling technologies, a vapor compression cycle (VCC) powered by an organic Rankine cycle (ORC) has the advantage of making use of the heat source throughout the year [13] to provide either cooling or electricity when cooling is not required [14]. Combined ORC-VCC systems in previous publications have used various working fluids: chlorofluorocarbons (CFCs), hydrochlorofluorocarbons (HCFCs) and hydrofluorocarbons (HFCs) [15, 16].

$\mathrm{CFC}$ and HCFC refrigerants have been largely replaced for new equipment in developed countries by HFC refrigerants, with zero ozone depletion potential (ODP), in compliance with the Montreal Protocol [17]. However, the environmental impact of a working fluid, when it escapes to the atmosphere, is not limited to stratospheric ozone layer depletion. In fact, while all HFCs are harmless to the earth's stratospheric ozone layer, some HFCs with large global warming potentials (GWP) could contribute significantly to climate change. HFCs were designated as greenhouse gases under the Kyoto Protocol in 1997 [18] and they are currently targeted by efforts to reduce greenhouse gas emissions in most developed countries. As a result, alternatives are sought for high GWP HFCs.

Attending to ORC systems, Quoilin et al. [19] highlighted that HFC-245fa is a common working fluid in commercial ORC installations, mainly used in low-temperature waste heat recovery. Moreover, they observed that, at the present time, most commercial ORC plants exhibit a simple architecture: sub-critical working conditions, single-component working fluids, single evaporation pressure, and possible use of a recuperator heat exchanger. Peris et al. [20] characterized experimentally an ORC module with a subcritical regenerative cycle configuration and HFC-245fa as working fluid, concluding that the ORC tested satisfies the main specifications for an efficient power system for low grade heat sources. Attending to environmental issues, HFC-245fa has a GWP of 858 [21]. Low-GWP working fluids have been recently proposed as potential replacements for HFC-245fa in various applications, including ORC systems. HCFO$1233 z d(E)$ [22] is a hydrochlorofluoroolefin (HCFO) with a GWP of 1 [21]. Despite the presence of chlorine in the molecule of HCFO-1233zd(E), its ODP has been estimated as a very low value of 0.00034 , due to its very short atmospheric lifetime [23] as compared to saturated chlorine-containing working fluids in current use (e.g. HCFC123 or HCFC-22). HFO-1336mzz(Z), also known as DR-2, is a hydrofluoroolefin (HFO) with a GWP of 2 [21] and zero ODP [24, 25]. Molés et al. [26] computed attractive performance of ORC systems using HCFO-1233zd(E) or HFO-1336mzz(Z) as the working fluids for low temperature heat recovery. They also found that cycle efficiency was benefitted substantially by the use of a recuperator. Table 1 shows the main thermophysical properties of HFC-245fa, HCFO-1233zd(E) and HFO$1336 \mathrm{mzz}(\mathrm{Z})$ and Figure 1 shows the temperature-entropy diagrams and vapor pressure curves for these three fluids. 
Fig. 1. T-s diagram and vapor pressure curves for HFC-245fa, HCFO-1233zd(E) and HFO-1336mzz(Z).

Table 1. Thermophysical properties of HFC-245fa, HCFO-1233zd(E) and HFO$1336 \mathrm{mzz}(\mathrm{Z})$.

Focusing on VCC systems, HFO-1234yf and HFO-1234ze(E) have been proposed [27] as alternatives for HFC-134a, a refrigerant with a GWP of 1,300 [21] that has been used extensively in refrigeration and air conditioning, including mobile air conditioning (MAC). HFO-1234yf and HFO-1234ze(E) have ODP values of zero [28], GWP values lower than 1 [21], low toxicity and mild flammability [29]. Some authors [30-32] have reported reductions in COP and cooling capacity when HFO-1234yf and HFO1234ze(E) are used as drop-in alternatives for HFC-134a. Mota-Babiloni et al. [33] presented an energy performance evaluation of HFO-1234yf and HFO-1234ze(E) as drop-in replacements for $\mathrm{HFC}-134 \mathrm{a}$, reporting $\mathrm{COP}$ reductions about 6\%. In this context, one way of increasing the COP of a VCC system is to increase the refrigerating effect in the evaporator by means of an internal heat exchanger (IHX) [34]. Molés et al. [35] studied different VCC configurations using HFO-1234yf and HFO-1234ze(E) as working fluids, highlighting that an IHX increases cooling capacity for all configurations studied and COP for the basic VCC configuration. Navarro-Esbrí et al. [36] reported experimentally observed reductions in cooling capacity and COP between 6-13\% upon drop-in replacement of HFC-134a with HFO-1234yf, moderated by the presence of an IHX. Table 2 shows the main thermophysical properties of HFC-134a, HFO-1234yf and HFO-1234ze(E) and Figure 2 shows the temperature-entropy diagrams and vapor pressure curves for these three fluids.

Fig. 2. T-s diagram and vapor pressure curves for HFC-134a, HFO-1234yf and HFO$1234 \mathrm{ze}(\mathrm{E})$.

Table 2. Thermophysical properties of HFC-134a, HFO-1234yf and HFO-1234ze(E).

Therefore, the aim of this work was to evaluate theoretically the energy performance of a combined organic Rankine cycle and vapor compression cycle system activated by low temperature heat sources and using low GWP fluids. The rest of the paper is organized as follows. In Section 2, the ORC-VCC system is described. In Section 3, the thermodynamic analysis is briefly explained. In Section 4, the results are shown and discussed. Finally, in Section 5, the main conclusions of the paper are summarized.

\section{ORC-VCC system description}

Figure 3 shows a schematic of the ORC-VCC system. As expected, this system consists of two cycles: the ORC (1-2-3-4-5-6-7-1) and the VCC (8-9-10-11-12-13-14-8). The two cycles are coupled, with the mechanical power from the ORC expander delivered to drive the compressor, thus eliminating the conversion losses associated with electrical 
motors and generators. The system uses different fluids in the ORC and VCC, allowing improved overall efficiency. The ORC includes an internal heat exchanger as a regenerator, using the superheat in the vapor exiting the expander to preheat the pressurized liquid entering the evaporator, reducing at the same time the thermal load on the condenser. The VCC includes an internal heat exchanger, which reduces the temperature of the subcooled refrigerant at the condenser outlet while increasing the temperature of the superheated refrigerant at the evaporator outlet. The vapor superheating resulting from the use of the internal heat exchanger causes the compressor discharge temperatures to increase well above the condensing temperatures. The significant amount of sensible heat available in the compressed vapor is transferred to preheat the ORC working fluid exiting the pump by means of the ORC-VCC recuperator. The overall system is an alternative to thermally activated cooling technologies with the advantage of providing mechanical power, or electricity, when cooling is not required.

Fig. 3. ORC-VCC system configuration.

\section{Thermodynamic analysis}

In order to develop a thermodynamic model of the combined ORC-VCC system, the following assumptions are made: steady-state conditions are considered in all components; heat and frictional losses are neglected; the power consumed by the condensers (e.g. for the operation of air fans or cooling water pumps) is assumed negligible, as it depends on the condenser design; the condensing temperatures in the two condensers are assumed equal, as a design constrain (the heat sink is assumed to be the same for both); the flow across the expansion valve is assumed isenthalpic; heat transfer in the ORC regenerator, the VCC IHX and the ORC-VCC system recuperator is calculated by specifying their heat exchanger effectiveness as defined below (developed with the hot side with minimum capacity); the liquid leaving either condenser is specified to have a subcooling of $5 \mathrm{~K}$ to prevent pump cavitation; the vapor leaving the ORC evaporator is specified to have a superheat of $5 \mathrm{~K}$ to ensure no presence of liquid in the expander; and the vapor leaving the VCC evaporator is specified to have a useful superheat of $10 \mathrm{~K}$ to ensure no presence of liquid in the compressor. The performance of the ORC-VCC system is assessed through two computed parameters: the thermal $\mathrm{COP}$, defined as the ratio of the rate of cooling and the thermal power consumption by the ORC evaporator and the electrical COP, defined as the ratio of the rate of cooling and the electrical power consumption by the ORC pump. Based on these assumptions and referring to the ORC-VCC system configuration presented in Fig 3, the mathematical model for the system is given below.

Heat exchangers effectiveness:

$$
\varepsilon=\frac{T_{h o t, \text { in }}-T_{h o t, \text { out }}}{T_{\text {hot }, \text { in }}-T_{\text {cold }, \text { in }}}
$$

For the ORC: 


$$
\begin{gathered}
\eta_{i s, x}=\frac{h_{5}-h_{6}}{h_{5}-h_{6, i s}} \\
W_{x}=\eta_{o, x} \dot{m}_{O R C}\left(h_{5}-h_{6}\right) \\
\eta_{i s, p}=\frac{h_{2, i s}-h_{1}}{h_{2}-h_{1}} \\
W_{p}=\frac{\dot{m}_{O R C}\left(h_{2}-h_{1}\right)}{\eta_{o, p}} \\
Q_{O R C}=\dot{m}_{O R C}\left(h_{5}-h_{4}\right) \\
\eta_{O R C}=\frac{W_{x}}{Q_{O R C}}
\end{gathered}
$$

For the VCC:

$$
\begin{gathered}
\eta_{i s, c}=\frac{h_{9, i s}-h_{8}}{h_{9}-h_{8}} \\
W_{c}=\eta_{o, c} \dot{m}_{V C C}\left(h_{9}-h_{8}\right) \\
Q_{V C C}=\dot{m}_{V C C}\left(h_{14}-h_{13}\right) \\
C O P_{V C C}=\frac{Q_{V C C}}{W_{c}}
\end{gathered}
$$

For the ORC-VCC system:

$$
\begin{gathered}
W_{c}=W_{x} \\
C O P_{T}=\frac{Q_{V C C}}{Q_{O R C}}=C O P_{V C C} \eta_{O R C} \\
C O P_{E}=\frac{Q_{V C C}}{W_{p}}
\end{gathered}
$$

The thermodynamic properties of HCFO-1233zd(E), HFO-1234yf and HFO-1234ze(E) were obtained from the Refprop database [37]. The thermodynamic properties of HFO$1336 \mathrm{mzz}(\mathrm{Z})$ were provided by DuPont. The basic operating parameters that determine the system performance are specified in Table 3. 
Table 3. Cycle operating parameters.

\section{Results and discussion}

The system performance was quantified in terms of the following metrics: ORC efficiency, VCC COP and the thermal and electrical COPs of the combined ORC-VCC system. The system performance was evaluated for four different combinations of working fluids in the ORC (HFO-1336mzz(Z) or HCFO-1233zd(E)) and in the VCC (HFO-1234yf or HFO-1234ze(E)). The cycle performance metrics were calculated over a range of values shown in Table 3 for the ORC evaporating temperature, the VCC evaporating temperature, the common ORC and VCC condensing temperature and the ORC-VCC recuperator effectiveness, presenting the results in Figures 4 to 7 . Input parameters were varied one at a time while keeping the remaining input parameters constant at the values shown in parentheses in Table 3.

The ORC efficiency, shown in Figure 4, varies between $10.6 \%$ and $15.0 \%$ depending on operating conditions. As expected, ORC efficiency increases with the ORC evaporating temperature and the ORC-VCC recuperator effectiveness and decreases with the VCC evaporating temperature and the condensing temperature. HFO-1336mzz(Z) shows higher ORC efficiency throughout the range of operating conditions studied, except for condensing temperatures higher than $320 \mathrm{~K}\left(47^{\circ} \mathrm{C}\right)$, for which $\mathrm{HCFO}-1233 \mathrm{zd}(\mathrm{E})$ shows higher ORC efficiency. Use of HFO-1234ze(E) as the VCC working fluid results in higher compressor discharge temperatures, higher amounts of heat contributed to the ORC-VCC recuperator and higher ORC efficiencies than use of HFO-1234yf at VCC evaporating temperatures in the range of operating conditions studied.

Fig. 4. ORC efficiency variation with ORC evaporating temperature, VCC evaporating temperature, condensing temperature and ORC-VCC recuperator effectiveness.

The VCC COP, shown in Figure 5, varies between 2.7 and 8.0, depending on the operating conditions. As expected, the ORC evaporating temperature, the ORC-VCC recuperator effectiveness and the choice of ORC working fluid have no influence on the VCC COP. The choice of VCC working fluid has only a minimal influence, with HFO$1234 z e(E)$ presenting slightly better results. The VCC COP increases with the VCC evaporating temperature and decreases with the condensing temperature.

Fig. 5. VCC COP variation with ORC evaporating temperature, VCC evaporating temperature, condensing temperature and $\mathrm{ORC}-\mathrm{VCC}$ recuperator effectiveness.

The thermal COP of the ORC-VCC system, shown in Figure 6, varies between 0.30 and 1.10. Similarly to ORC efficiency, HFO- $1336 \mathrm{mzz}(\mathrm{Z})$ realizes a lightly higher combined cycle thermal COP throughout the range of operating conditions studied. The thermal COP increases significantly with VCC evaporating temperature and decreases significantly with condensing temperature. 
Fig. 6. Thermal COP variation with ORC evaporating temperature, VCC evaporating temperature, condensing temperature and ORC-VCC recuperator effectiveness.

Figure 7 presents the electrical COP of the ORC-VCC system, which is related to the ORC pump consumption. Electrical COP values range between 15 and 110, depending on the operating conditions. Throughout the range of operating conditions studied, use of HFO-1336mzz(Z) as the ORC working fluid results in significantly higher electrical COP due to the lower pump power consumption relative to HCFO-1233zd(E). ORCVCC recuperator effectiveness has no influence on the electrical COP. Contrary to the thermal COP, electrical COP decreases with increasing ORC evaporating temperature. Electrical COP also decreases with increasing condensing temperature and increases with increasing VCC evaporating temperature.

Fig. 7. Electrical COP variation with ORC evaporating temperature, VCC evaporating temperature, condensing temperature and $\mathrm{ORC}-\mathrm{VCC}$ recuperator effectiveness.

\section{Conclusions}

A computational analysis of the performance of a combined organic Rankine cycle and vapor compression cycle system activated by low temperature heat sources, and using low GWP fluids was carried out. The proposed combined cycle could be viewed as an alternative to the absorption cooling cycle with the advantage of providing mechanical power or electricity, when cooling is not required. The system used different working fluids in the ORC and VCC, thus allowing an improved overall efficiency. The choice of VCC working fluid showed only a limited influence on system efficiency, with HFO$1234 z e(E)$ presenting slightly better results. The thermal COP of the ORC-VCC system varied between 0.30 and 1.10; it increased with the ORC and VCC evaporating temperatures and the ORC-VCC recuperator effectiveness and decreased with the condensing temperature. Use of HFO-1336mzz(Z) as the ORC working fluid resulted in slightly higher system thermal efficiency throughout the range of operating conditions studied. The electrical COP of the ORC-VCC system, which is related to the ORC pump consumption, varied between 15 and 110, depending on the operating conditions. Use of HFO-1336mzz(Z) as the ORC working fluid resulted in substantially higher system electrical efficiency than use of HCFO-1233zd(E) throughout the range of operating conditions studied.

\section{Acknowledgements}

The authors thankfully acknowledge DuPont Corporation for supporting this work.

\section{References}

[1] R. Best, W. Rivera, A review of thermal cooling systems, Applied Thermal Engineering 75 (2015), $1162-1175$. 
[2] D. Sonar, S.L. Soni, D. Sharma, Micro-trigeneration for energy sustainability: Technologies, tools and trends, Applied Thermal Engineering 71 (2014), 790 - 796.

[3] U. Jakob, U. Eicker, D. Schneider, A.H. Taki, M.J. Cook, Simulation and experimental investigation into diffusion absorption cooling machines for airconditioning applications, Applied Thermal Engineering 28 (2008), 1138 - 1150.

[4] A. González-Gil, M. Izquierdo, J.D. Marcos, E. Palacios, Experimental evaluation of a direct air-cooled lithium bromide-water absorption prototype for solar air conditioning, Applied Thermal Engineering 31 (2011), 66 - 80.

[5] F. Calise, High temperature solar heating and cooling systems for different Mediterranean climates: dynamic simulation and economic assessment, Applied Thermal Engineering 32 (2012), 108 - 124.

[6] T. Núñez, W. Mittelbach, H.M. Henning, Development of an adsorption chiller and heat pump for domestic heating and air-conditioning applications, Applied Thermal Engineering 27 (2007), 2205 - 2212.

[7] R.Z. Wang, Efficient adsorption refrigerators integrated with heat pipes, Applied Thermal Engineering 28 (2008), 317 - 326.

[8] F. Aghbalou, A. Mimet, F. Badia, J. Illa, A. El Bouradi, J. Bougard, Heat and mass transfer during adsorption of ammonia in a cylindrical adsorbent bed: thermal performance study of a combined parabolic solar collector, water heat pipe and adsorber generator assembly, Applied Thermal Engineering 24 (2004), 2537 - 255.

[9] N.M. Khattab, A novel solar-powered adsorption refrigeration module, Applied Thermal Engineering 24 (2004), 2747 - 2760.

[10] H. Li, Y.J. Dai, Y. Li, D. La, R.Z. Wang, Experimental investigation on a one-rotor two-stage desiccant cooling/heating system driven by solar air collectors, Applied Thermal Engineering 31 (2011), 3677 - 3683.

[11] Z.Q. Xiong, Y.J. Dai, R.Z. Wang, Investigation on a two-stage solar liquiddesiccant ( $\mathrm{LiBr}$ ) dehumidification system assisted by $\mathrm{CaCl}_{2}$ solution, Applied Thermal Engineering 29 (2009), 1209 - 1215.

[12] X. Ma, W. Zhang, S.A. Omer, S.B. Riffat, Experimental investigation of a novel steam ejector refrigerator suitable for solar energy applications, Applied Thermal Engineering 30 (2010), 1320 - 1325 .

[13] H. Wang, R. Peterson, K. Harada, E. Miller, R. Ingram-Goble, L. Fisher, J. Yih, C. Ward, Performance of a combined organic Rankine cycle and vapor compression cycle for heat activated cooling, Energy 36 (2011) $447-458$.

[14] H. Wang, R. Peterson, T. Herron, Design study of configurations on system COP for a combined ORC (organic Rankine cycle) and VCR (vapor compression cycle), Energy 36 (2011) 4809 - 4820. 
[15] M. Dubey, S.P.S. Rajput, P.K. Nag, R.D. Misra, Energy analysis of a coupled power - refrigeration cycle, Proceedings of the Institution of Mechanical Engineers Part A: Journal of Power and Energy 224 (2010) 749 - 759.

[16] S. Aphornratana, T. Sriveerakul, Analysis of a combined Rankine-vapour compression refrigeration cycle, Energy Conversion and Management 51 (2010) 2557 2564.

[17] United Nations Environment Program (UNEP), Montreal Protocol on Substances that Deplete the Ozone Layer, Final Act, United Nations, New York, 1997.

[18] Kyoto Protocol, Report of the Conference of the Parties, United Nations Framework Convention on Climate Change (UNFCCC), 1997.

[19] S. Quoilin, M. Van Den Broek, S. Declaye, P. Dewallef, V. Lemort, Technoeconomic survey of Organic Rankine Cycle (ORC) systems, Renewable and Sustainable Energy Reviews 22 (2013) 168 - 186.

[20] B. Peris, J. Navarro-Esbrí, F. Molés, R. Collado, A. Mota-Babiloni, Performance evaluation of an Organic Rankine Cycle (ORC) for power application from low grade heat sources, Applied Thermal Engineering 75 (2015), 763 - 769.

[21] G. Myhre, D. Shindell, F.-M. Bréon, W. Collins, J. Fuglestvedt, J. Huang, D. Koch, J.F. Lamarque, D. Lee, B. Mendoza, T. Nakajima, A. Robock, G. Stephens, T. Takemura and H. Zhang, 2013: "Anthropogenic and Natural Radiative Forcing", In: Climate Change: The Physical Science Basis. Contribution of Working Group I to the Fifth Assessment Report of the Intergovernmental Panel on Climate Change [T.F. Stocker, D. Qin, G.-K. Plattner, M. Tignor, S.K. Allen, J. Boschung, A. Nauels, Y. Xia, V. Bex and P.M. Midgley (eds.)], Cambridge University Press, Cambridge, United Kingdom and New York, NY, USA.

[22] G. Zyhowski, A. Brown, Low Global Warming Fluids for Replacement of HFC245fa and HFC-134a in ORC Applications, ORC 2011 Delft Presentation, 2011.

[23] K.O. Patten, D.J. Wuebbles, Atmospheric lifetimes and ozone depletion potentials of trans-1-chloro-3,3,3-trifluoropropylene and trans-1,2-dichloroethylene in a threedimensional model, Atmos. Chem. Phys. Discuss., 10, 16637-16657, 2010.

[24] K. Kontomaris, B. Minor and B. Hydutsky, Low GWP Working Fluid for Organic Rankine Cycles: DR-2; Chemical Stability at High Temperatures, 2nd International Seminar on ORC Power Systems, ASME ORC 2013, Rotterdam, The Netherlands, Oct. 7-8, 2013.

[25] K. Kontomaris, HFO-1336mzz-Z: High temperature chemical stability and use as a working fluid in Organic Rankine Cycles, 15th International Refrigeration and Air Conditioning Conference at Purdue, West Lafayette, Indiana, USA, July 14-17, 2014.

[26] F. Molés, J. Navarro-Esbrí, B. Peris, A. Mota-Babiloni, A. Barragán-Cervera, K. Kontomaris, Low GWP alternatives to HFC-245fa in Organic Rankine Cycles for low 
temperature heat recovery: HCFO-1233zd-E and HFO-1336mzz-Z, Applied Thermal Engineering, doi: 10.1016/j.applthermaleng.2014.06.055.

[27] M.O. McLinden, A.F. Kazakov, J.S. Brown, P.A. Domanski, A thermodynamic analysis of refrigerants: possibilities and tradeoffs for low-GWP refrigerants, International Journal of Refrigeration 38 (2014) 80 - 92.

[28] World Meteorological Organization (WMO), Scientific Assessment of Ozone Depletion: 2006, Global Ozone, Research and Monitoring Project - Report 50, Geneva, Switzerland, 2007.

[29] M. Koban, HFO-1234yf Low GWP Refrigerant LCCP Analysis, SAE Technical Paper 2009-01-0179, doi: 10.4271/2009-01-0179.

[30] C. Zilio, J.S. Brown, G. Schiochet, A. Cavallini, The refrigerant HFO-1234yf in air conditioning systems, Energy 36 (2011), 6110 - 6120.

[31] J. Navarro-Esbrí, J.M. Mendoza-Miranda, A. Mota-Babiloni, A. Barragán-Cervera, J.M. Belman-Flores, Experimental analysis of HFO-1234yf as a drop-in replacement for HFC-134a in a vapour compression system, International Journal of Refrigeration 36 (2012), $870-880$.

[32] D. Leighton, Y. Hwang, R. Radermacher, Modelling of household refrigerator performance with low global warming potential alternative refrigerants, ASHRAE Transactions 118 (2012), 658 - 665.

[33] A. Mota-Babiloni, J. Navarro-Esbrí, A. Barragán, F. Molés, B. Peris, Drop-in energy performance evaluation of R1234yf and R1234ze(E) in a vapor compression system as R134a replacements, Applied Thermal Engineering 71 (2014) 259 - 265.

[34] C. Wang, System performance of R-1234yf refrigerant in air-conditioning and heat pump system - An overview of current status, Applied Thermal Engineering 73 (2014) $1412-1420$.

[35] F. Molés, J. Navarro-Esbrí, B. Peris, A. Mota-Babiloni, A. Barragán-Cervera, Theoretical energy performance evaluation of different single stage vapour compression refrigeration configurations using R1234yf and $\mathrm{R} 1234 \mathrm{ze}(\mathrm{E})$ as working fluids, International Journal of Refrigeration 44 (2014) 141 - 150.

[36] J. Navarro-Esbrí, F. Molés, A. Barragán-Cervera, Experimental analysis of the internal heat exchanger influence on a vapour compression system performance working with HFO-1234yf as a drop-in replacement for HFC-134a, Applied Thermal Engineering 59 (2013), 153 - 161.

[37] E.W. Lemmon, M.L. Huber, M.O. McLinden, REFPROP, NIST Standard Reference Database 23, v.8, National Institute of Standards, Gaithersburg, MD, USA, 2007. 

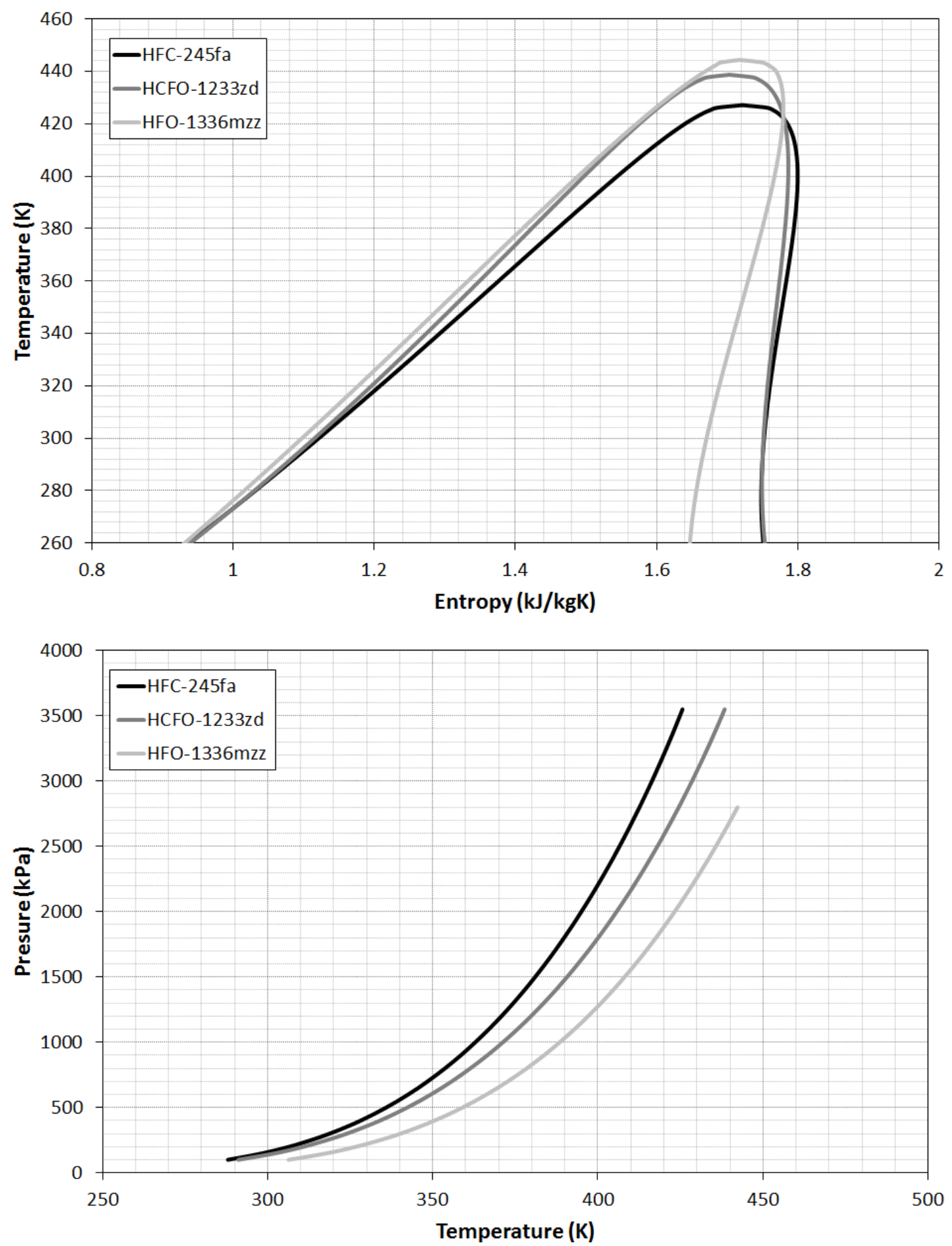

Fig. 1. T-s diagram and vapor pressure curves for HFC-245fa, HCFO-1233zd(E) and HFO-1336mzz(Z). 

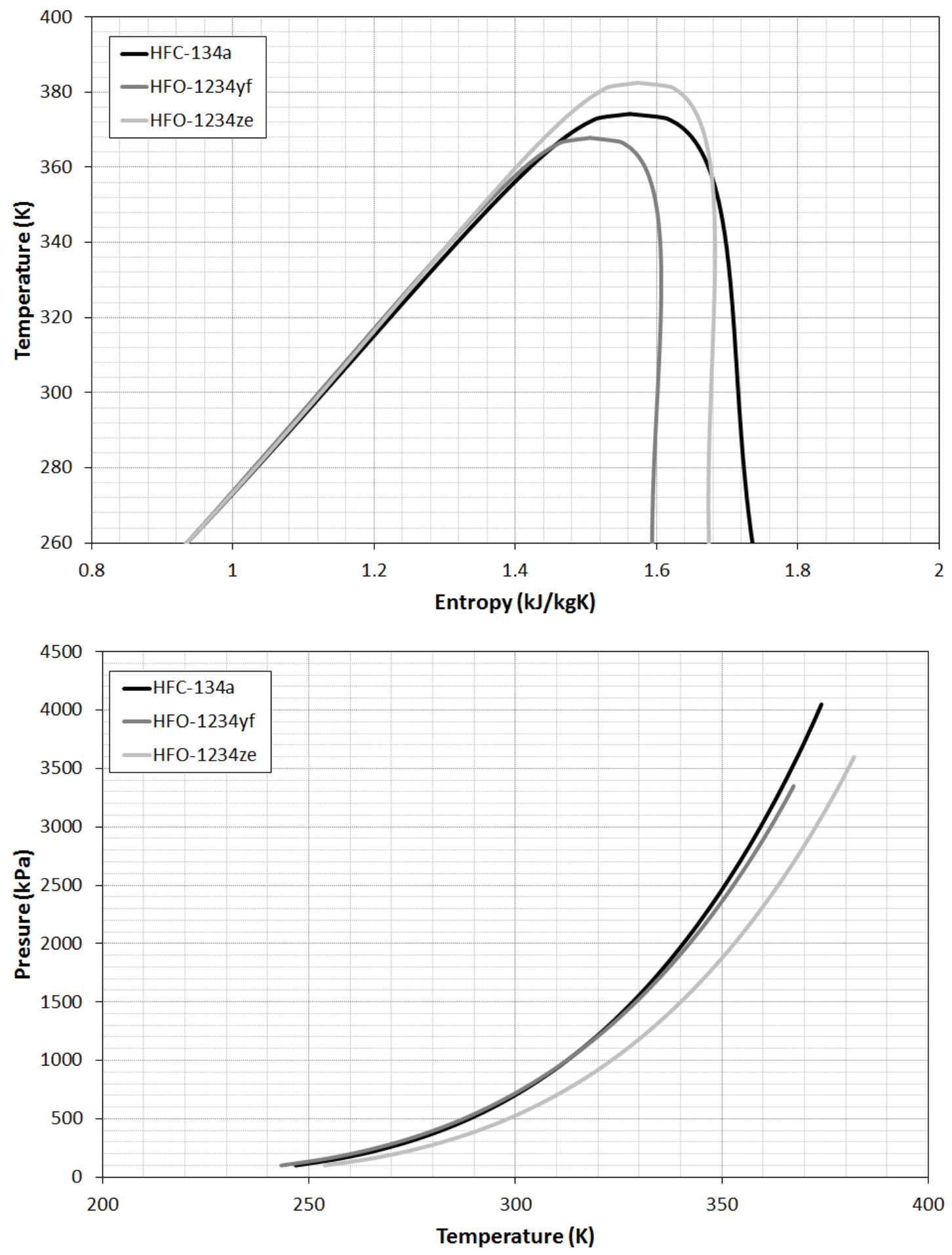

Fig. 2. T-s diagram and vapor pressure curves for HFC-134a, HFO-1234yf and HFO1234ze(E). 


\section{ORC}

\section{VCC}
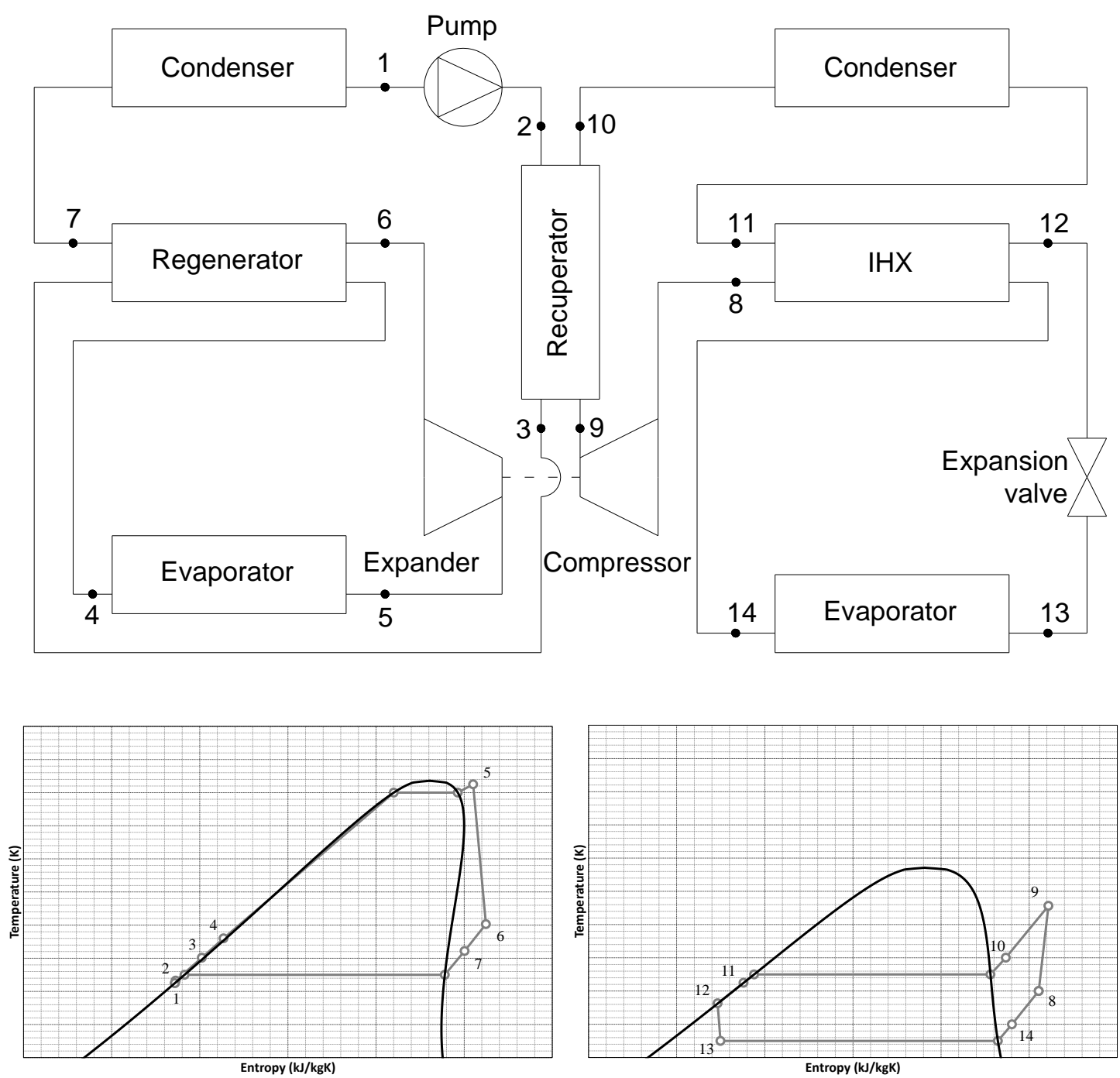

Fig. 3. ORC-VCC system configuration. 


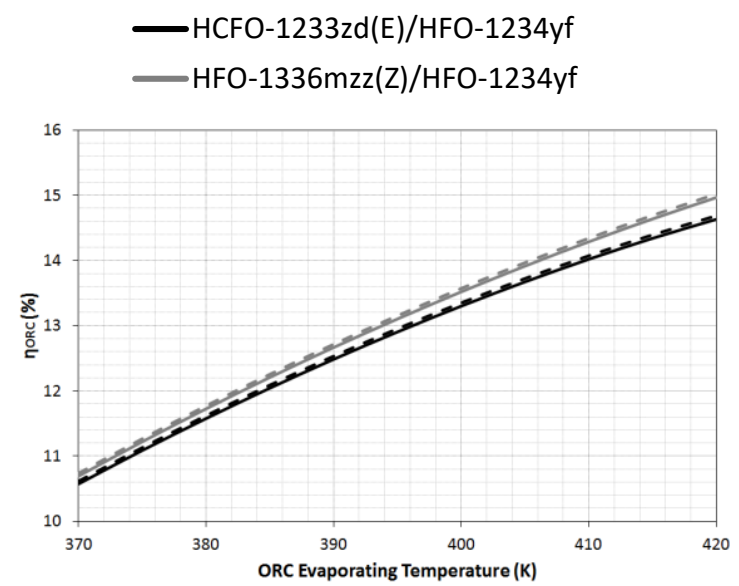

- -HCFO-1233zd(E)/HFO-1234ze(E)

- -HFO-1336mzz(Z)/HFO-1234ze(E)
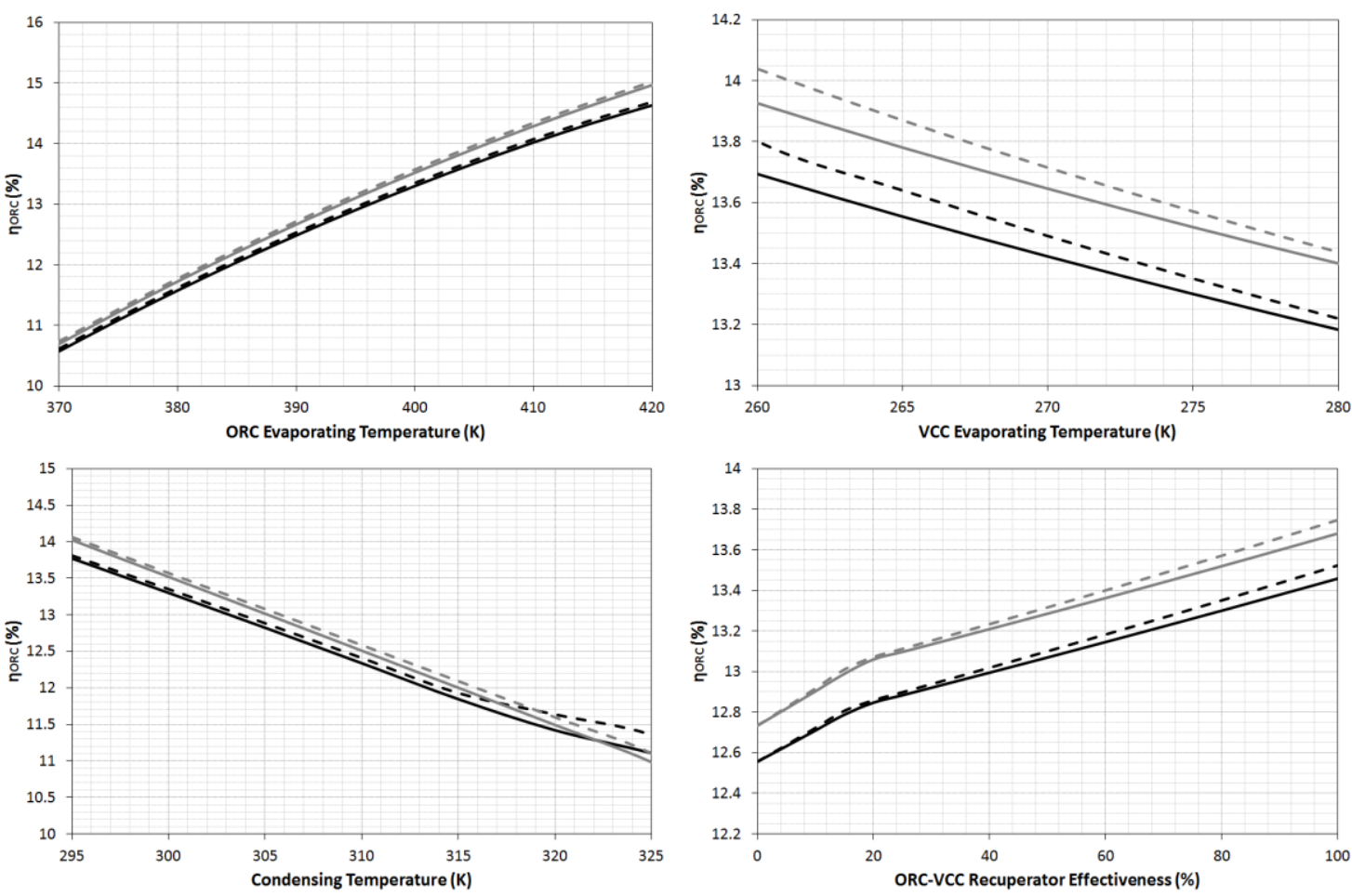

Fig. 4. ORC efficiency variation with ORC evaporating temperature, VCC evaporating temperature, condensing temperature and ORC-VCC recuperator effectiveness. 

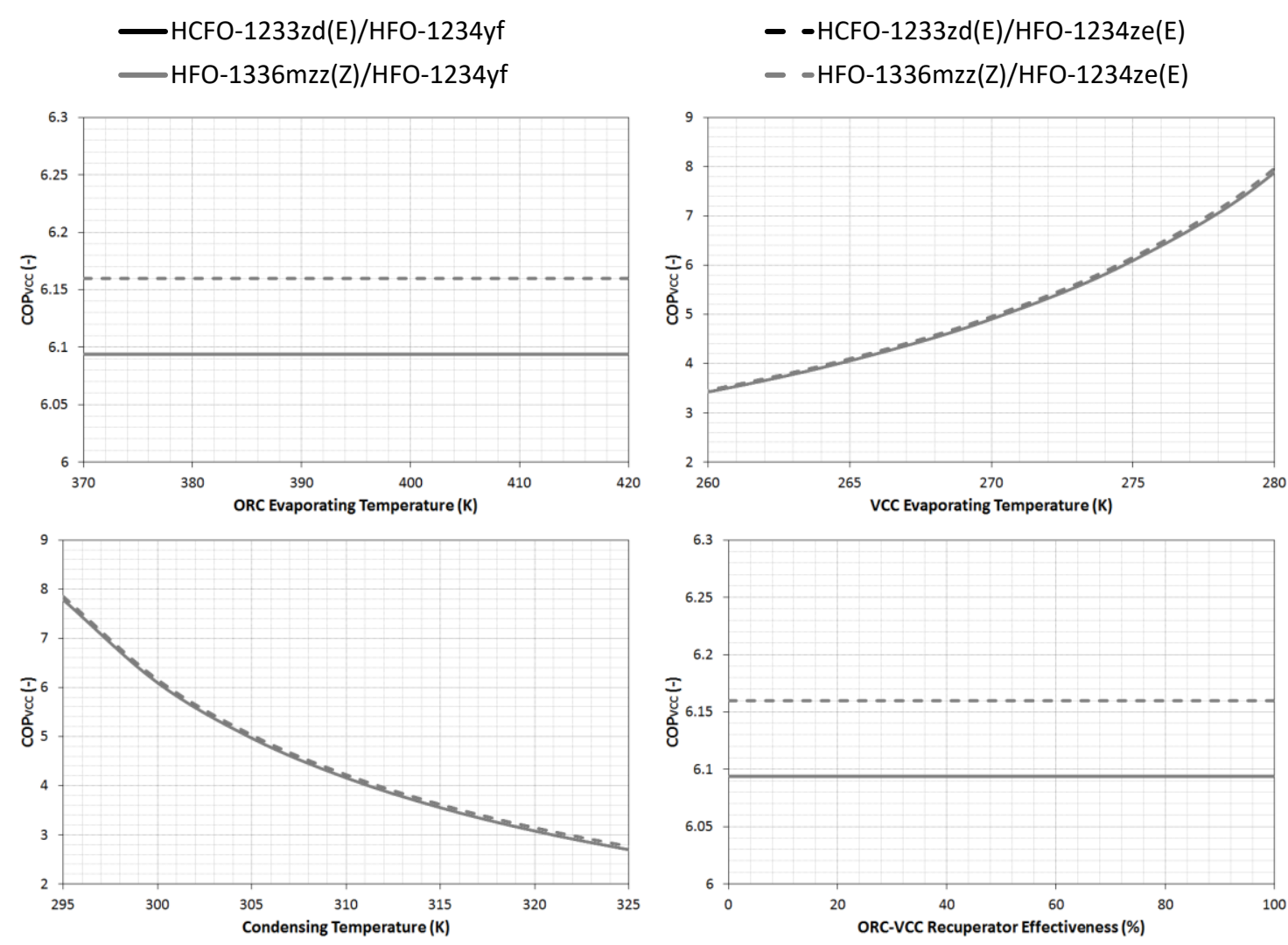

Fig. 5. VCC COP variation with ORC evaporating temperature, VCC evaporating temperature, condensing temperature and $\mathrm{ORC}-\mathrm{VCC}$ recuperator effectiveness. 


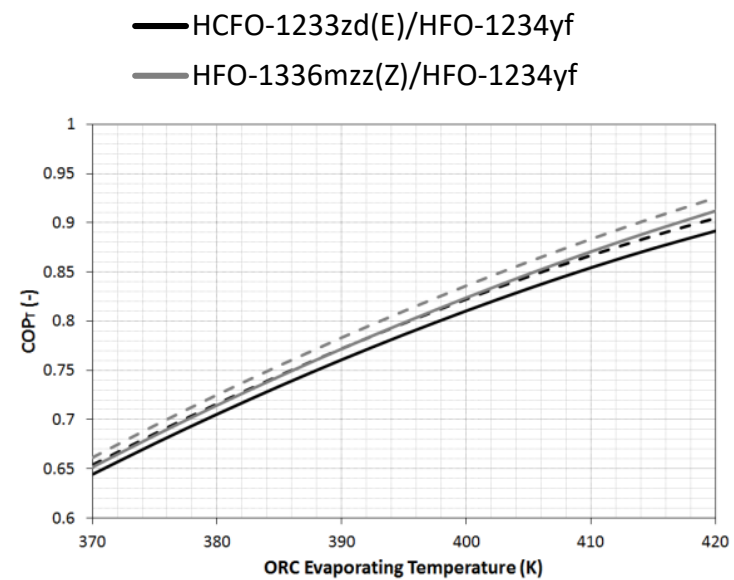

- -HCFO-1233zd(E)/HFO-1234ze(E)

- -HFO-1336mzz(Z)/HFO-1234ze(E)
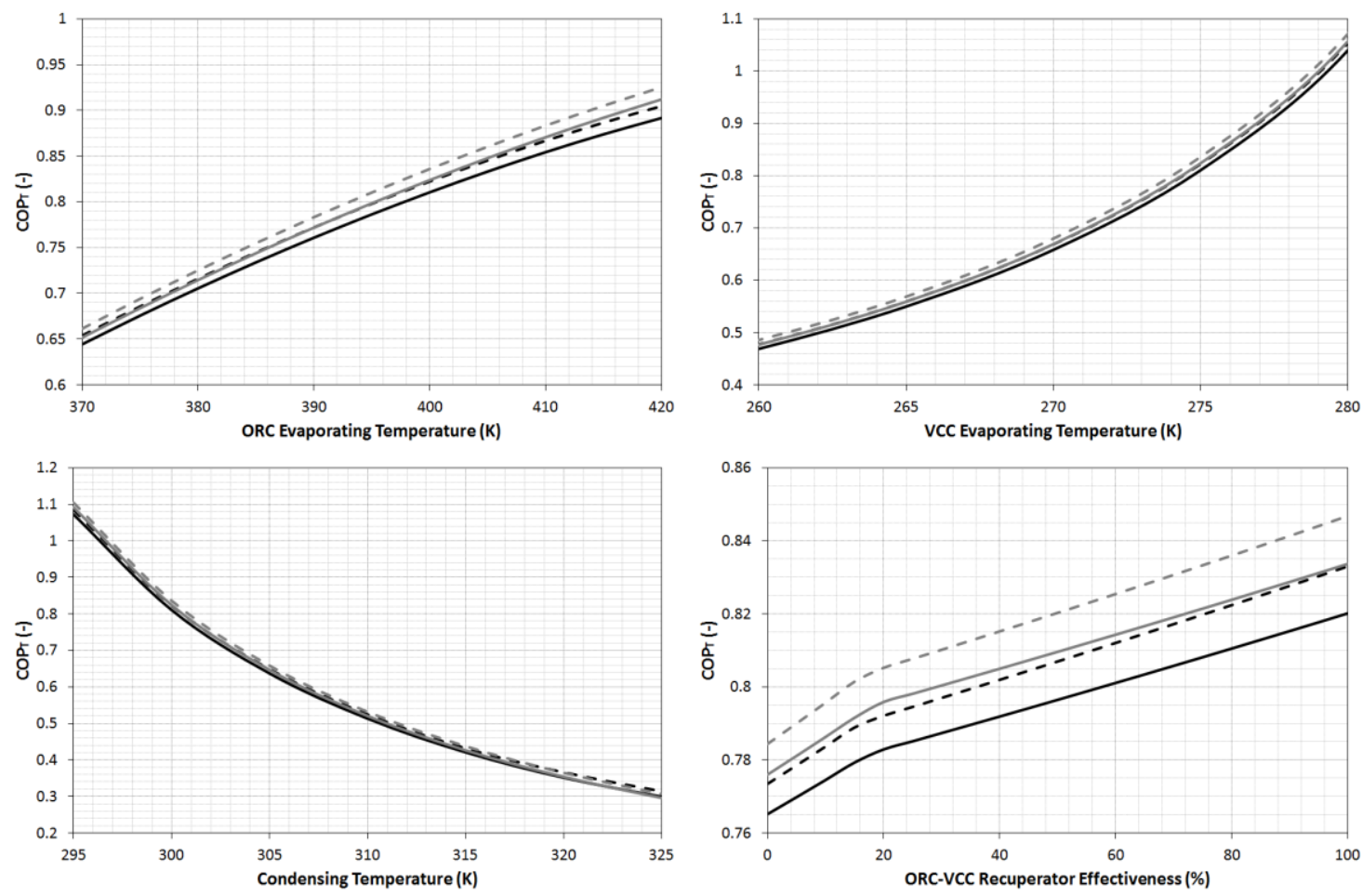

Fig. 6. Thermal COP variation with ORC evaporating temperature, VCC evaporating temperature, condensing temperature and $\mathrm{ORC}-\mathrm{VCC}$ recuperator effectiveness. 


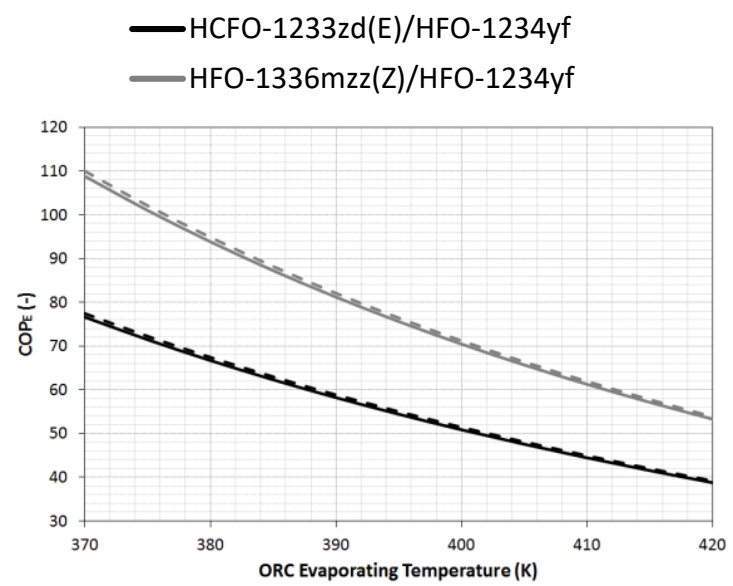

- -HCFO-1233zd(E)/HFO-1234ze(E)

- -HFO-1336mzz(Z)/HFO-1234ze(E)
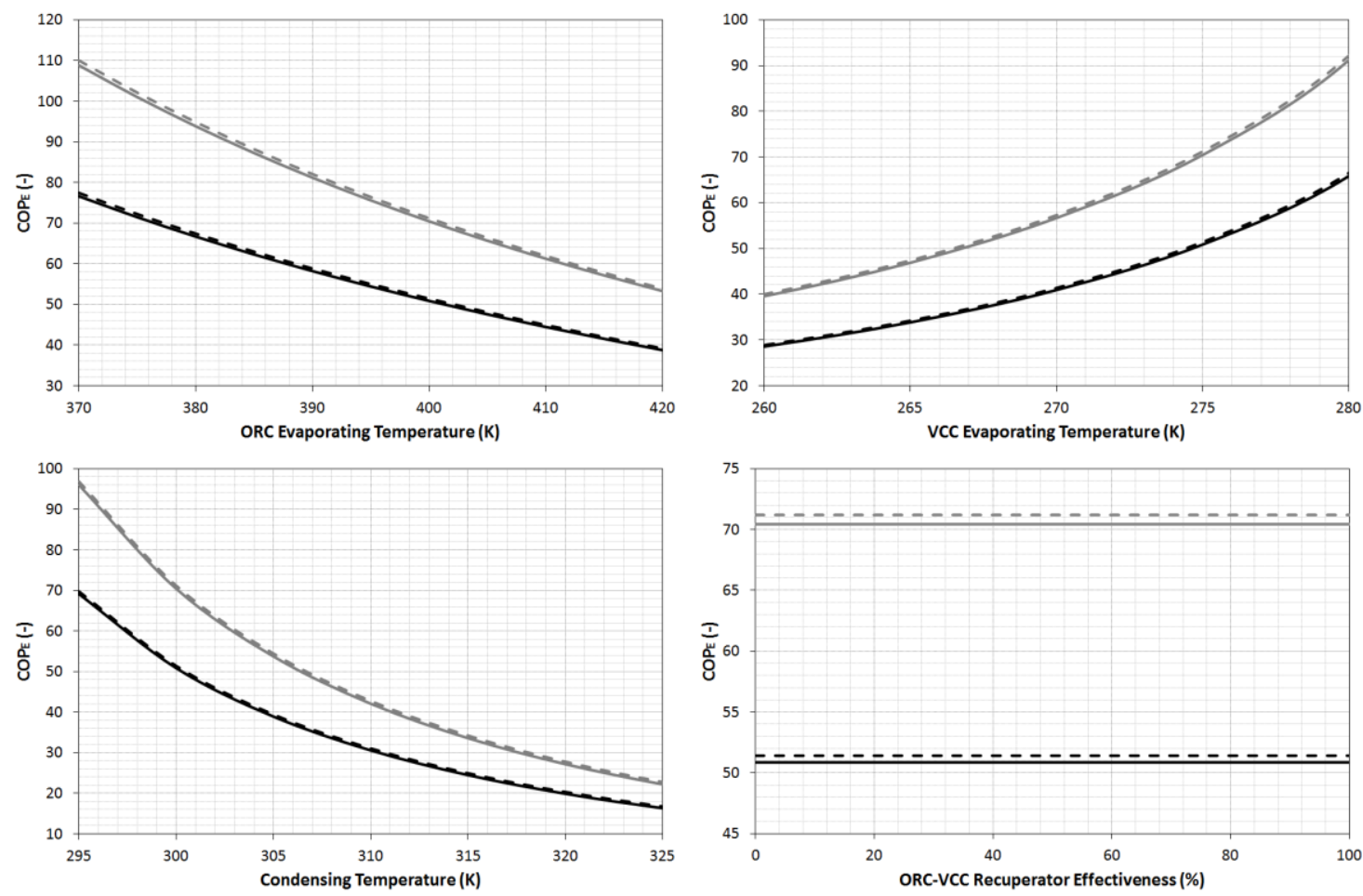

Fig. 7. Electrical COP variation with ORC evaporating temperature, VCC evaporating temperature, condensing temperature and ORC-VCC recuperator effectiveness. 


\section{FIGURE CAPTIONS}

Fig. 1. T-s diagram and vapor pressure curves for HFC-245fa, HCFO-1233zd(E) and HFO-1336mzz(Z).

Fig. 2. T-s diagram and vapor pressure curves for HFC-134a, HFO-1234yf and HFO$1234 \mathrm{ze}(\mathrm{E})$.

Fig. 3. ORC-VCC system configuration.

Fig. 4. ORC efficiency variation with ORC evaporating temperature, VCC evaporating temperature, condensing temperature and $\mathrm{ORC}-\mathrm{VCC}$ recuperator effectiveness.

Fig. 5. VCC COP variation with ORC evaporating temperature, VCC evaporating temperature, condensing temperature and ORC-VCC recuperator effectiveness.

Fig. 6. Thermal COP variation with ORC evaporating temperature, VCC evaporating temperature, condensing temperature and ORC-VCC recuperator effectiveness.

Fig. 7. Electrical COP variation with ORC evaporating temperature, VCC evaporating temperature, condensing temperature and ORC-VCC recuperator effectiveness. 
Table 1. Thermophysical properties of HFC-245fa, HCFO-1233zd(E) and HFO$1336 \mathrm{mzz}(\mathrm{Z})$.

\begin{tabular}{cccc}
\hline Parameters & HFC-245fa & $\begin{array}{c}\text { HCFO- } \\
\text { 1233zd(E) }\end{array}$ & $\begin{array}{c}\text { HFO- } \\
\text { 1336 mzz(Z) }\end{array}$ \\
\hline Critical temperature (K) & 427.16 & 438.75 & 444.45 \\
Critical pressure (MPa) & 3.65 & 3.57 & 2.9 \\
Molecular weight (kg/kmol) & 134 & 130.5 & 164 \\
Slope & Dry & Dry & Dry \\
OEL (ppm) & 300 & 800 & $500^{(*)}$ \\
Flammability & Non flammable & Non flammable & Non flammable \\
ALT $(\mathrm{yr})$ & $7.7^{(* *)}$ & $0.0712^{(* *)}$ & $0.0602^{(* *)}$ \\
ODP & 0 & 0.00034 & 0 \\
GWP & $858^{(* *)}$ & $1^{(* *)}$ & $2^{(* *)}$ \\
Normal boiling point $(\mathrm{K})$ & 287.96 & 291.12 & 306.55 \\
Latent heat at boiling point $(\mathrm{kJ} / \mathrm{kg})$ & 196.23 & 195.52 & 165.67 \\
\hline
\end{tabular}

(*)DuPont Allowable Exposure Limit (AEL); (**) [21] 
Table 2. Thermophysical properties of HFC-134a, HFO-1234yf and HFO-1234ze(E).

\begin{tabular}{cccc}
\hline Parameters & HFC-134a & HFO-1234yf & $\begin{array}{c}\text { HFO- } \\
\text { 1234ze(E) }\end{array}$ \\
\hline Critical temperature $(\mathrm{K})$ & 374.21 & 367.85 & 382.52 \\
Critical pressure $(\mathrm{MPa})$ & 4.06 & 3.38 & 3.64 \\
Molecular weight $(\mathrm{kg} / \mathrm{kmol})$ & 102 & 114 & 114 \\
Slope & Isentropic & Isentropic & Isentropic \\
OEL (ppm) & 1,000 & 500 & 800 \\
Flammability & Non flammable & Mild $^{(*)}$ & Mild $^{(*)}$ \\
ALT $(\mathrm{yr})$ & $13.4^{(* *)}$ & $0.0287^{(* *)}$ & $0.0274^{(* *)}$ \\
ODP & 0 & 0 & 0 \\
GWP & $1,300^{(* *)}$ & $<1^{(* *)}$ & $<1^{(* *)}$ \\
Normal boiling point $(\mathrm{K})$ & 246.79 & 243.37 & 253.89 \\
Latent heat at boiling point $(\mathrm{kJ} / \mathrm{kg})$ & 217.16 & 180.40 & 195.60 \\
\hline
\end{tabular}

(*) Flammability class 2L according to ASHRAE Standard 34; (**) [21] 
Table 3. Cycle operating parameters.

\section{Parameters}

ORC and VCC condensing temperatures

ORC evaporating temperature

VCC evaporating temperature

ORC evaporator superheat

VCC evaporator superheat

ORC and VCC condenser subcooling

ORC regenerator effectiveness

VCC IHX effectiveness

ORC-VCC recuperator effectiveness

Isentropic efficiencies $\left(\eta_{i s, x}, \eta_{i s, c}, \eta_{i s, p}\right)$

Overall efficiencies of expander and compressor

$$
\left(\eta_{o, x}, \eta_{o, c}\right)
$$

\section{Numeric values}

$295 \mathrm{~K}-325 \mathrm{~K}(300 \mathrm{~K})$

$370 \mathrm{~K}-420 \mathrm{~K}(400 \mathrm{~K})$

$260 \mathrm{~K}-280 \mathrm{~K}(275 \mathrm{~K})$

$5 \mathrm{~K}$

$10 \mathrm{~K}$

$5 \mathrm{~K}$

$80 \%$

$80 \%$

$0 \%-100 \%(80 \%)$

$80 \%$

$75 \%$

Overall efficiency of pump $\left(\eta_{o, p}\right)$

$45 \%$ 